\section{BOOK AND MEDIA REVIEW}

\section{The Complete Guide to Fertility Awareness}

Jane Knight. Abingdon, UK: Routledge, 2017. ISBN-13: 978-1-138-79010-0. Price $\mathrm{f} 29.99$.

Pages: 448 (paperback)

This book is an extensive update of the 1996 edition, Fertility: Fertility Awareness and Natural Family Planning. The first and second editions of this book (written by Elizabeth Clubb and Jane Knight) have been extremely important sources of information on fertility awareness. Consequently I am really pleased to finally see a new edition published. The original book comprised 192 pages (the new edition has 448 pages), so this is an extensive update of the book and justifies the descriptor 'Complete Guide'.

There are 20 chapters: Part one contains chapters on fertility awareness, male fertility, female fertility, temperature, cervical secretions, cervix, calendar calculations, minor indicators of fertility, combining indicators, simplified methods, and factors affecting the menstrual cycle. Part two's chapters cover how to use fertility awareness to avoid becoming pregnant. There are chapters on fertility awareness methods and women with normal fertility; women ceasing both hormonal and non-hormonal contraception and changing to fertility awareness; breastfeeding and the lactational amenorrhea method and returning fertility; and a chapter on the perimenopause. The third section covers how to achieve pregnancy through fertility awareness, and the fourth section how to teach fertility awareness. In the appendices there are useful fertility awareness charts, plus a guide to drugs that affect the menstrual cycle. The book is referenced throughout.

This is such a useful and interesting book. Students often struggle with the fertile time in the cycle and how to calculate this, and there are clear instructions on how to do this in the chapter on female fertility. My only criticism of the book is the lack of colour drawings and pictures, as I think this would have aided learning. There are self-assessment questions with answers at the end of each chapter, which is helpful for checking one's understanding of the topic.

The chapter on factors affecting fertility awareness in the menstrual cycle covers areas including shift work, stress, and disorders such as premenstrual syndrome, polycystic ovary syndrome, abnormal bleeding, hyperprolactinemia, thyroid dysfunction, and endometriosis. There is a section on the impact of acute illness and breast cancer treatment. These topics are discussed and their impact on the menstrual cycle and fertility addressed. Often these are topics that are not covered in books yet they are problems that affect many of the women whom we see in clinic, and who perhaps struggle to find solutions to their particular issues, hence this book is an excellent resource.

Written by an expert in this field, this is a very readable and clear book, and would be suitable both for health professionals and for women who are interested in this topic either as a contraceptive method or to aid pregnancy. In conclusion, I'd say that this book is a seminal text on fertility awareness, and I'm not aware of another book that addresses this area so comprehensively.

Reviewed by Su Everett

Middlesex University, Archway Campus, The Burroughs, London NW4 4BT, UK; s.everett@mdx.ac.uk

Competing interests None declared.

\section{Provenance and peer review}

Commissioned; internally peer reviewed.

(C) Faculty of Sexual and Reproductive Healthcare of the Royal College of Obstetricians and Gynaecologists (unless otherwise stated in the text of the article) 2017. All rights reserved. No commercial use is permitted unless otherwise expressly granted.

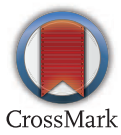

J Fam Plann Reprod Health Care 2017;43:236. doi:10.1136/jprhc-2017-101770 